\title{
Exploring leadership coaching as a tool to improve the people management skills of information technology and cybersecurity project managers
}

\author{
Darrell Norman BURRELL, \\ The Florida Institute of Technology, Melbourne, Australia \\ dburrell@claremontlincoln.edu
}

\begin{abstract}
According to recent research 55 percent of information technology (IT) projects are deemed unsuccessful. In 2016, globally, organizations waste an average of \$97 million dollars for every \$1 billion invested information technology projects. These numbers should be of tremendous concern when these projects often focus on critical operational aspects like knowledge management, data analytics, intellectual property, cybersecurity, and information management. These numbers also point the critical need to develop leadership skills for information technology project managers. This paper explores the need and viability for organizations to invest in leadership coaching as employee development tools for their IT project managers and cybersecurity technical staffers.
\end{abstract}

Keywords: Information Technology Project Management, Cybersecurity Project Management, Technology Management

JEL Classification: 022, O32, M10.

\section{Introduction}

Previously it was understood that having a project manager with technical skills was the principal acute aspect in successful project management but research has postulated the critical significance of leadership skills as an often overlooked aspect of project success or failure (Thompson, 2010). Despite the existence of project managers with technical expertise around project management the number of failed projects is still high (Thompson, 2010; Hyvari, 2006; Florentine, 2017). 55 percent of IT projects fail or are deemed unsuccessful (Florentine, 2017). In 2016, globally, organizations waste an average of \$97 million dollars for every $\$ 1$ billion invested information technology projects (Florentine, 2017). These numbers should be of tremendous concern when these 
projects often focus on critical operational aspects like knowledge management, data analytics, intellectual property, cybersecurity, and information management. These numbers also point the critical need to develop leadership skills for information technology project managers. It is believed that leadership is a needed competency for successful project outcomes (Thompson, 2010).

Attaining effective project results necessitate the amalgamation of technical and leadership capabilities (Thompson, 2010). Many project management methods and practices (planning, scheduling, control, and automated tools) exist for tracking, quantifying, and project outcomes. Often what is missing is ability to understand and measure human elements of managing people such as team cohesion, managerial communication, engagement, motivation, interpersonal relations, conflict management, loyalty, and trust (Thompson, 2010). As a result the development of leadership skills around the engagement, motivation, and management of people is a critical aspect of improving the quality of project outcomes (Thompson, 2010).

The quality of relationship between managers and their subordinates continues to be a key factor accomplishment of organizational project goals (Thompson, 2010). As a result is the most successful organizations in project management tend to focus resources in development of human capital (Florentine, 2017). That means, investing in the development and improvement of people leadership proficiently in a manner that considers these investment just as important as the development of information technology, project management skills, and technical skills (Florentine, 2017). For information technology project managers, business leadership skills are becoming just as important as project management skills due to the digital convergence and interconnection between business operations and technical operations (Florentine, 2017).

Leadership strategy, actions, and behaviors play a significant role in project strategy, team cohesiveness, team communication, team trust, project team motivation and project team commitment (Thompson, 2010). The absence of effective leadership skills increases that risk of project failure (Thompson, 2010). Thite (2000) proposed that exposure and leadership coaching around leadership skills affords project managers with more operative tools to manage projects more efficiently and effectively. Thite (2000) further suggested that project managers need people leadership skills to better management the human or people elements that are a critical aspect of managing the project team members.

Currently, career development, primarily professional and leadership development remains a low priority for cybersecurity and information technology professionals (Oltsik, 2017). According to (Oltsik, 2017) technical 
professionals need to develop leadership skills just as they need to develop technical skills. Lester and Parnell (2006) outline that many organizations promote technical personnel into management positions believing that technical expertise transfers directly into leadership competencies. However, the professional capacities required of high performing technical experts might not be the same skills required in leadership roles (Lester and Parnell, 2006). Technical competence does not transfer into people and project managerial competence as technical skills involve analytical and design whereas the managerial role requires people skills, decision-making, and teambuilding competencies (Goldberg, 2006; Rothenberger, 2016; Dzameshie, 2012).

According to Boyd (2018) being successful as a cybersecurity project and people manager requires more than just understanding technology. Effective leadership in cybersecurity and information technology requires managers at all level to develop some soft skills related to communication, strategic decision making, and employee management (Boyd, 2018). Cybersecurity and information technology project managers need the communication, writing, and strategic thinking skills more than ever because they are often required to justify equipment and software purchases that can run from hundreds of thousands to millions of dollars (Boyd, 2018) This requires an ability to understand and communicate strategically to senior leaders and project team members (Boyd, 2018). This communications with leaders outside of the cyber realm requires the ability to understand the value and gracefully articulate organizational importance of needed resources (Boyd, 2018). Most technical degree programs or certifications do not teach these skills to cybersecurity leaders, hence induction and growth of executive coaching as a leadership development tool.

\section{Leadership coaching}

The popularity of coaching as a practice to attain projects' success is increasing worldwide (Lebian, 2011, McCarhty, 2011). Researches conforming effective interrelation between coaching and successful project management (McCarthy, 2011). Organizations spend a year 2 billion dollars, globally, in procurement of coaching services (Walker-Fraser, 2011).

The purpose of this paper is to explore coaching as a developmental practice to investigate the effectiveness of executive coaching as an integrated intervention that enhances leadership competencies and project management success through the lens of growing volume of literature on the value and benefits of executive coaching through exploration of the following questions: 
- How effective is executive coaching to achieve project management success?

- How effective is coaching on organizational productivity?

- What is the role of executive coaching practice on building business-oriented skills and competencies?

- Can any business implement the coaching to serve productivity and effectiveness, or implementing coaching requires special characteristics?

Recently, the executive coaching developed to become the trendiest practice to construct the organizational effectiveness and efficiency (Newsome \& Dent, 2011). Further, coaching emerged to become the most reputable business methods to construct leadership development and business sustainability (Kampa- Kokesh \& Anderson, 2005; Newsome \& Dente, 2011).

According to Kampa- Kokesh and Anderson (2005), the executive coaching practice appeared in the late 1940s. The practice started to operate as an affiliation of the consulting profession and psychologist's science. Thus, researching the literature to explore the history of the coaching intervention leads to discover six important topics including: a) definitions and interpretations; (b), objectives and goals; (c) methodologies; (d) relevance to psychology; (e) therapy and coaching skills; (f) recipients and advantages of users (Kampa- Kokesh \& Anderson, 2005).

\section{Definition and Conceptual Understanding}

As its broadest status, coaching is primarily defined as "process of equipping people with tools, knowledge, and opportunities they need to develop them and become more effective" (Peterson \& Hicks, 1995, p: 41). The coaching was technically was classified as a technique or a tool that management can utilize to increase performance as factor to achieve projects' success and business sustainability. Further, in the 1990 executive coaching emerged urgently in the business industry as an intervention to change the management conduct of managers, project managers and leaders in the middle and senior-level to improve the technical perception of project selection and quality management (Peterson \& Hicks, 1995).

In the leadership literature, (Feldman, 2001) specified the three major basis factors of executive coaching profession including: (a) one-on- one training and mentoring; (b) it requires the implementation of 360- feedback on managers; (c) coaching target to enhance executives, leaders, and project managers competencies and effectiveness. Similarly, the consulting psychology 
literature referred to the same factors as Feldman identification to construct the definition and understanding of executive coaching (2001). Furthermore, Definitions and understanding of executive coaching vary in accordance with perspectives, philosophy, approach, and professional and contextual objective and reason for coaching (Newsome and Dent, 2011).

Literature pertaining coaching imposes the necessity to provide a theoretical insight and explanation about leadership and collateral theories in order to present an academic and empirical vision about coaching practice. Nevertheless, leadership has attracted the interest and curiosity of academic researchers and scholars worldwide. Further, a wide academic literature and research with different theoretical methods implemented to analyze and explain the arduousness complexity of leadership practice (Northouse, 2013). Literature review and books implemented many definitions and interpretations about leadership.

Vugat, Hogan, and Kaiser discussed the abroad and different approaches that researchers utilized to define leadership. Researchers expressed continuously that leadership has a long developing history. Vugat et.al argued that leadership may emerge as a therapy and solution to group and people and communication and collaboration challenges and difficulties (2008).

Senge in his book the The Fifth Discipline: The Art of \& Practice of Learning Organization quoted a statement for Confucius that had said more than twenty-five years ago,

"To become a leader, you must first become a human being", Confucius created a developmental theory dealing with the seven "meditative spaces" (2006). Senge (2006) delivered and explained Confucius's vision about the collateral connection between leadership and wisdom, and assuring that wisdom is one of the oldest competencies of leadership. Unfortunately, the leadership perspective has almost lost the compass of the art of leading in today's business industry. The concept and logic about leadership has lost and suffered technical and contextual confusion under the harsh parturition of innovation and technology (Senge, 2006).

Vugat, Hogan, and Kaiser (2008) discuss the misconception of the leadership phenomenon in today's perception for leading people. Further, Vugat, Hogan, and Kaiser (2008) argued that the misunderstanding based on the tendency to perceive leadership from the authority and power point of view. The Vugat, Hogan, and Kaiser (2008) study analyzed Leadership from three different perceptions of the conventional wisdom. First, leadership must be assessed in an equation that composed of leadership and followership (Vugat, Hogan, \& Kaiser, 2008). Seconds, leadership must be studied from a psychological basis of both 
leaders and followers who might not always converge (Vugat, Hogan, \& Kaiser, 2008). Third, the modern leadership evaluation must take in consideration the recent technological and international factors and changes that played a role to evolve the perception of leadership (Vugat, Hogan, \& Kaiser, 2008).

However, evaluation of leadership coaching is significantly different from other approaches to leadership development. Leadership coaching is widely defined in the perception of the developmental relationship between a coach and a client which required enhancing the client's leadership competencies to be an effective manger (Ely, Boyce, Nelson, Zaccaro, Broome, and Whyman, 2010).

\section{The Interrelation between Coaching and Performance and Project Management}

In the literature investigating the interrelation between coaching and the success of project management and increasing business performance, the coaching illustrated as a tool that serve strategically the interest of project managers to achieve projects success and increase the employees performance ( Walker-Fraser, 2011). However, despite the popularity of coaching as an intervention to increase the business productivity, yet, the empirical studied concerning the validity of coaching as a practice is scarce (CIPD, 2010). The Chartered Institute of Personnel and Development (CIPD) investigated the dimensions of coaching as a learning to develop performance that leads to a major factor of the success of project management success (CIPD, 2010). Moreover, CIPD established an investigation to verify the impact of coaching a developmental tool for leadership and project management. The survey implemented an investigation of $729 \mathrm{HR}$ managers and representatives that reported the positive impact of coaching a developmental technique to achieve project management success (CIPD, 2010; Saowalux, \& Peng (2007).

In the literature involving the examination of coaching as an emerging intervention to accomplish project management success, many researchers tried to verify the aspects of coaching as a leadership integrated development phenomenon. Therefore, the aspects that is presented in the literature to study coaching as a project management practice including: (a) credentials or skills for choosing a coach; (b) personal and professional attributes for effective executive coach; (d), pros and cons for internal and external executive coach; (e), the perception of the engagement of executive coaching; (f), specifications of coaching techniques and tools; (f) signs of executive coaching success; (g), learning, conduct, and culture change resulted from executive coaching (KampaKokesh \& Anderson, 2005; Newsome \& Dente, 2011). 


\section{Methodologies to the Coaching Process in Project Management}

Despite the fact that the standards of the coaching process are fairly the same among all, however, the approaches implemented by coaches to implement changes through executives, project managers and organizational leadership culture mainly depend on the professional and technical background of coaches and their intellectual and academic philosophes. Hence, there are five main approaches for executive coaching that were presented by Pltier (2001) which was updated by Newsome and Dente (2011), the five approaches are: psychodynamic, behaviorist, person-centered, cognitive therapeutic, and systemoriented (Newsome and Dente, 2011)

\subsection{Psychodynamic Approach}

In this approach psychologists are utilized to help executives obtain a psychological scientific background and competencies to increase their ability to understand the way their people think, feel, and react in the workplace (Pltier, 2001; Lebian, 2011). Additionally, with this approach, psychologists help executives and leaders to improve their vision of themselves and other and how to manage their employees effectively in accordance with this vision (Labian, 2011). Gary et.al presented an argument in his research claimed that psychologists are the most qualified to be coaches (2011).

However, the qualifications of the coaching profession as developmental tool are not regulated with a disciplinary competency frame (Vugat, Hogan, Kaiser, 2008) Therefore, some researchers stated that psychologists are the most qualified for the coaching practice. Thus, the characteristics and skills of the psychologists are the qualifications required to executive coaching role, such as, professionalism, communication and listening skills, understanding the psychology of human-inner are the characteristics that a the coach should attain. Feldman \& Lankau achieved a study that tested 87 executive coaching participants and presented their findings of the necessary qualifications of executive coaching are identical to the psychologists' attributes and expertise in order to create the reorganizational development and change towards success and sustainability (Feldman \& Lankau, 2010, Journal of Management, 2005).

\subsection{Behaviorist Approach}

In this approach, the focus on changing the behavior through observation rather than through inner-status of the coach (Macarthey, Milner, 2011). The 
practitioners suggested two leadership approaches to represent the behavioral approach including transformational and transactional (Khan et.al, 2012). According to Khan et.al (2012), the transformational and the transactional are the best leadership style that executive coaches must implement to achieve the behavioral coaching approach. A survey was implemented by Khan Et.al to prove this vision; a number of 280 questionnaires were established to confirm this hypothesis.

\subsection{Cognitive Therapy Approach}

This approach based on the theory of the cognitive psychology that executive coaches must learn to their own thoughts and visions to be able to change their employees (Pettier, 201; Strange, 2011). Strange confirmed that the cognitive psychology approach is an effective managerial development technique to achieve project management success. However, the validity of this approach requires executing a supportive mentoring strategies and a special organizational culture (2011).

\subsection{System-Oriented Approach}

In this approach the coach required to understand the work atmosphere and the factors that might affect the executives and employees behavior (Peltier, 2001; Strange, 2011). In this approach the coach needs to know the whole organizational system with its complexities, challenges, stakeholders, culture, and market requirements in order to be able to create an effective mentoring strategies that are system-oriented ( Peltier 2001; Strange, 2011).

\subsection{Executive Coaching Competencies impact on strategic Project management Effectiveness}

The popularity of coaching is emerging worldwide in business and academia (Lebian, 2011). The Chartered Institute of Personnel and Development (CIPD) (2011) survey regarding the prevalence of coaching as a practice to increase organizational effective reflected that \% 90 of participants claimed that coaching is a recommended tool for individual and organizational development (Candis \& Magnolia, 2010). Researchers and scholars are in constant debate about the strategic credentials and attributes that coaching must possess to help achieve project management effectiveness and organizational sustainability. Therefore, the International Federation raised a deep concern regarding the unregulated system of competencies and skills for the executive coaching 
profession (McCarthy \&Miller, 2011). Nevertheless, in the strategic project management, Laufer (2012) established nine managerial practices to support the guidance of the operational and strategic organizational development, and to help systemize the executive coaching professional basis. The Laufer's nine leadership practices are embraced by executive coaches in the strategic coaching process to improve the organizational effectiveness and performance (Hannafy \& Vitulano, 2013). The nine Laufer (2012) leadership practices that are considered by researchers as key strategic practices for executive coaching process (Hannafy \& Vitulano, 2013). The nine leadership practices are: 1) Embrace the living order; 2) challenge the status quo; 3 ) Fit the project activities to the proper context; 4) Recruiting the right people is a priority; Create the productive culture; 5) Concentrate on effective communication skills, 6) Planning and monitoring are daily strategies; 8) Focus on results; and 9) lead by example in order to manage successfully. Additionally, many researchers suggested systematic coaching approach as a strategy to create a systematical change in organizations (Feldman \& Lankau, 2010; Journal of Management, 2005). The systematic coaching change could be managed by executives and top management; however, they must execute a framework that including systematic managerial practices to achieve the targeted change (Feldman \& Landau). The Laufer's managerial practices are tools and techniques that coaches might utilize to lead organizational systematic and organizational change (Laufer, 2012). Thus, systematic change process is a strategic brand that refers to systemize logical integration through a coaching framework (Wood, 2011).

Nevertheless, the systematic coaching process requires the executive coaches to possess keen managerial skills in order to be able to implement the necessary coaching framework that Laufer suggested as a leadership strategic plan to create systematic change (2012). Further, the requirements for leaders and executive coaches to implement the systematic change in organizations are multi-facet as a result of challenges and complexities (ICF, 2011; McCarthy \&Miller, 2011). In addition, Luntz (2011) presented nine principles to the project management profession "leading to manage" including: people- centeredness; (b) paradigm-breaking; (c), passion; (d) perfection; (e) prioritization; (f) persistence; (g) persuasion; (h) partnership; and (g) principled-action (Luntz, 2011). Luntz's principles are factors for strategic project management to lead organizations to wining market positioning (Luntz, 2011, Ely, 2010). The nine principles of Lutz can be implemented by executive coaches to clarify the vision of the daily operational activities and dues. Additionally, in the coaching process of project management development, the executives are required to construct a special coaching model that correlate with the internal organizational vision, 
mission, goals and cultures; and that interact with the external opportunities, weakness and challenges of the market (Mayfield \& Mayfield, 2012; Feldman, 2010). The luntz's leadership principles might help identifies a systematic culture to organizational learning (Walker-Frazer, 2011). For organizations, the value of coaching and mentoring exists in the quality culture that caries the organizational values, norms, and principles (Freedman \&Perry, 2010).In other words, the Lutz leadership principles and Laufer practices are a strategic and effective coaching framework for organizational culture to enhance organizational learning of project management (Laufer, 2012; Lutz, 2011; Freedman \& Perry, 2010).

\section{Coaching as an Organizational Behavior and System Thinking}

The latest researches documented effective outcomes of the success on the nature of the relationship between the behavioral system approach and executive coaching (Visser, 2010). The studies stated productive organizational operational outcomes on performance and sustainability (Visser, 2010). According to skinner, the behavioral system approach includes the behavioral of an organization and the system approach under the guidance of the coaching practice (2007). Skinner implemented a comprehensive theoretical framework includes the explanation and illustration of the development of the system approach under the practice of the executive coaching (2007).

Effective organizational behavior is a strategic and operational activity that requires a behavioral transition in the business perception of its vision, goals, objectives, and culture to accomplish the targeted connectivity with organizational productivity and performance (Visser, 2010). In viewing the relating basis of coaching process and behavioral system; researchers state the executive coaching as a systemic behavioral practice. The behavioral system supported coaches with three systematic developmental lessons (Wasylyshyn, 2003). The first lesson reflects the importance of the daily interaction between the coach and the employees to change the thinking status and mental states (Wasylyshyn, 2003). Further, mentoring the daily operational interaction helps polishing the human system thinking (Visser, 2010). The psychodynamic and cognitive approaches concentrate on the importance of coaching the personal needs, desires, and attitude to steering the success and productivity of a project (Wasylyshyn, 2003). The second, this lesson concentrates on the philosophy that the coach must give attention and mentoring to the present time and setting behavior rather than building assumptions and judgments of the past behavior (Thomas et al., 2007; Westerman, 1998). However, the psychodynamic and many other humanitarian approaches suggest the importance of analyzing the past 
causes and motives of the inner-psychic to solve the present conflicts. Thus, the behavioral system approach that coach must pay attention to the "now- and here "theory in dealing with the present complexities and challenges (Thomas et al., 2007; Westerman, 1998).

The third lesson states that the coach is allowed to be manipulative in order to achieve the success of behavioral system approach (Thomas et al., 2007; Westerman, 1998). Further, the behavioral system suggests manipulation as a coaching technique to improve and develop many organizational gaps (Thomas et al., 2007; Westerman, 1998). However, psychodynamic and cognitive approaches object to the usage of the manipulation as a strategic tool to solve operational problem and develop organizational and individual strategic gaps (Visser, 2010). Additionally, the cognitive psychodynamic approaches classified the manipulative tool as unethical and against the professional and ethical values (Visser, 2010).

\section{Organizational Change to Effectiveness through Executive Coaching}

Many organizations and industries are in a time of rapid change and progress caused by the emergence of technology. The development and progress that occurred in the communications and networking technology have changed the management styles and philosophies (Dey, 2009). However, to compete in this dynamic, many organizations are implementing technology and innovation to manage and empower its effectiveness. Increasingly, organizations are utilizing Project Support Office (PSO) as an organizational entity to assist project managers in implementing the project management techniques, methodologies, and tools to coach and mentoring the project management success. According to Wysocki (2014) PSO can help the coaching process by providing administrative and operational support in according with projects' goals and objectives. The managers can utilize the six functions of POS to support the success of the coaching process to achieve the organizational effectiveness goal. The POS six functions are: project support, coaching and mentoring, standards and methods, development and staffing, decision-making, performance-enhancement, and measurement-reporting (Wysocki, 2014). The POS is established primarily to foster the processes, techniques, and practices of project management (Pellegrinelli, 2011). Furthermore, the PSO is a challenge for many companies and requires a status of suitability to be incorporated to its system (Pellegrinelli, 2011). The challenges including: lack of leadership support, lack of compelling business status, the involvement of strict performance standards for program suitability and effectiveness (Wysocki, 2014). The POS has a maturity version 
which is called PMMM that provides the project managers and executive coaches with ten valuable administrative, operational, and technical practices to reflect management maturity including: communication management, procurement management, risk-management, and integration-management (Pellegrinelli, 2011); Wysocki, 2014). Kaleshovaska (2014) states that most organizations have found PSO and PMMM as a valuable project management asset for effective and efficient organizations that enable them to respond to dynamic environment and challenging and changing markets. Additionally, executive coaches and leaders who are interested to attain sustainable growth and achieve a competitive edge in the market must pay a serious attention to incorporating technology and innovation in their organizational leadership and management (Kaleshovaska, 2014).

In this section, an illustration of the impact of executive coaching on improving the portfolio management with its selection, performance and evaluation is implemented. To explain, the organizational core has shifted to the usage the management of variable projects. The shift of the streamline in the management line of organizations requires implementation of new technological tools, techniques, and development portfolio product (Wysocki, 2014). Furthermore, the necessity for developing an efficient portfolio project system is a demandingly emerging as the science of portfolio management. In lieu of this demand, the project management institute (PMI) strived nearly for the last ten decades to provide the required knowledge, studies, tools, programs, researches, Coaching and mentoring, and technology to satisfy the needs of the project management field and business area (Wysocki, 2014). Nevertheless, the PMI institute involved in issuing a coaching and mentoring programs that support the project and portfolio management discipline (Wysocki, 2014). The PMI programs concentrate on coaching professional training, issues PM certificates, lectures for PM tests through media interaction, and executive coaching training for executives and project managers (PMI, 2013). Hence, organizations are motivated to train its executives and top management to be qualified for executive coaching and professional project managers to achieve the effectiveness and the competitive management quality in the market.

In accordance with Artto and Dietrich (2014) the project managers are responsible to execute the strategies to help the organizational objectives to be linked to operational goals. The linkage programs are implemented through a professional coaching program process that begins with initiation and moving to planning, executing and controlling until the closing date of the process (Artto and Dietrich, 2014).

The coaching professional programs that organizations implement with the supervision of either a contracted external trained coach certified by (Project 
Management Institute) PMI, or an internal trained executive coach, lead the firm to mentoring the achievement of the five project portfolio management stages including:

1. Process Initiation: put a clear work plan including the projects' schedules, recruiting the qualified staff, staffing the working teams, assigning responsibilities and decision-making authorities, setting the proper standards and principles for the working culture (Artto and Dietrich 2014).

2. The planning stage: this stage documents all the details of project management process such as, stating the project process dates, signing the experts and experienced staff, and a comprehensive budgeting plan.

3. Executing process: in this stage a, execution for strategies to manage challenges, performance objectives, analyzing and operating risks, and addressing all the dimensions of the accomplishment of the project and the interest of the stakeholder.

4. Controlling and Maintaining Stage: a clear plan to maintain the time schedule, budget and financial plan, and the closing constraints of the project

5. The Closing Stage:

Thus, the PMI model of the project management and portfolio management presents a mentoring guidance to the executive coach to succefully and efficiently complete the project with an international quality standards and a competitive international management scope (Artto and Dietrich 2014).

\section{Coaching and Organizational Resistance Change}

Organizational change is the strategy of an organization to target a future movement toward a desired goal to increase its productivity, effectiveness, and operational and market development away from its present condition (Lunerburge, 2010). Further, organizations are urged to change as a result of many global and national economic, technological and market competitiveness pressure and challenges (Lunerburge, 2010). In this process the role of executive coaching is strategically intense and divers (Creemers, 2011). According to Creemer, there are many reasons that cause organizational resistance to change such as: 1) Dislike of change, 2) the concern about the new system, 3) lack of capability of leaders to prepare organizations to change, and, 4) lack of leadership's competencies to prepare for the future required as operational strategies and planes (2011). Thus, the resistance to change can be reduced dramatically by implementing a therapy program that clarify all the internal and 
external factors that cause and effect the change transition, and educate employees about the process (Creemer, 2011)

Moreover, leaders and executive coaches' role is to initiate change and decrease the organizational resistance to change (Creemers, 2011). In addition, the PMI initiated a guidance program to help executive coaching implement to overcome organizational resistance to change (Creemers, 2011). The PMI program includes the following items to develop an organization through resistance to change stated by Duke (2011) and Anderson (2011) including:

1. Learning and Communication

Organizational resistance to change can be eliminated an intensive coaching effort to educate employees about change and the factors behind and benefits from it

(Duke, 2011). Executive coaches must communicate with people in the firm and assure their readiness and recognition of the change process including causes and effects (Duke, 2011).

2. Participation and Involvement

Executive coaching process must include the involvement of employee and staff in the changing making and implementation process. The involvement and participation of organizational employee through specify problems and the plans to solving them reduce organizational resistance to change (Anderson, 2011; Lunerburge, 2010).

3. Organizing and Support

The executive coach must issue strategic plan stating the leadership behavior and the organizational culture to organize the operational transition to change. This program of leaders' behavior reduces transitional tension which helps will organizational resistance to change (Anderson, 2011).

4. Negotiation, Cooptation and settlement process

Executive coaching process includes the negotiation process with the managers and experts to help lead the changing process and be part of the future staff of the organization. The cooptation involves choosing a group of leaders that have a decision-making authority to manage the organizational change transition (Anderson, 2011; Lunerburge, 2010).

Hence, the executive coaching is a strategic factor to assure organizational change success and effectiveness (Spector, 2011). The executive coaching is a prominent basis and the operational backbone for the change initiative and accomplishment especially as it relates to cybersecurity and information technology project managers. 


\section{Discussions, Leadership complexities and challenges}

The Burrell Leadership Intricacy Model (2017) outlines eleven critical themes that make leading today and the future so challenging to such a level that investment in leadership development interventions is not an organizational luxury it is a paramount operations strategy. These themes were developed through several focus group interviews with members technical managers that attended the 2017 International Studying Leadership Conference at the University of Richmond in Richmond VA, USA.

\begin{tabular}{|c|c|}
\hline $\begin{array}{l}\text { Intricacy } \\
\text { variables }\end{array}$ & Burrell Leadership Intricacy Model (2017) \\
\hline Theme 1 & $\begin{array}{l}\text { Managerial retrospection does not lead to foresight since the variables and } \\
\text { conditions of internal and external environment can be in unremitting instability, } \\
\text { which make adaptability and change management skills precious. }\end{array}$ \\
\hline Theme 2 & $\begin{array}{l}\text { Exchanges and engagements between system elements are nonlinear and } \\
\text { interconnected in such a way that small alterations can manufacture inexplicably } \\
\text { sizeable impacts and consequences. }\end{array}$ \\
\hline Theme 3 & $\begin{array}{l}\text { Information in both the international and external environment is often exceedingly } \\
\text { overloaded, uncertain, incomplete, or indecipherable. }\end{array}$ \\
\hline Theme 4 & $\begin{array}{l}\text { Innovations, breakthroughs, and solutions can be developed from the congruent } \\
\text { dynamics within the organizational system and cannot be imposed from external } \\
\text { forces with inevitable and predictable outcomes. }\end{array}$ \\
\hline Theme 5 & $\begin{array}{l}\text { New technologies are disrupting mature work practices, shifting the nature of old } \\
\text { communication approaches, and taxing elderly collaboration approaches. }\end{array}$ \\
\hline Theme 6 & $\begin{array}{l}\text { Expertly comprehending the most effective and efficient ways to leverage } \\
\text { organizational strengths and industry best practices is one of the most critical duties } \\
\text { of leadership. }\end{array}$ \\
\hline Theme 7 & $\begin{array}{l}\text { Traditional organizational boundaries are dissolving in ways that necessitate } \\
\text { unlocked transparency, flexible hierarchies, dispersed resources, distributed } \\
\text { decision-making, loosening of centralized controls to foster the development of an } \\
\text { organizational learning culture at every level of the organization. }\end{array}$ \\
\hline Theme 8 & $\begin{array}{l}\text { Increased globalization and enlarged employee diversity will require fresh levels of } \\
\text { cooperation, pioneering ways of thinking, modern ways of comprehension that } \\
\text { require respect, learning-centered curiosity, sympathy, and empathy. }\end{array}$ \\
\hline Theme 9 & $\begin{array}{l}\text { The ability to tap into the organization's expertise talent and collective intelligence } \\
\text { are the most valuable organizational asset. }\end{array}$ \\
\hline Theme 10 & $\begin{array}{l}\text { Social capital and the ability to tap into expertise and knowledge networks are very } \\
\text { critical because they provide access to data and information that is essential to } \\
\text { complex problem solving and effectual decision-making, }\end{array}$ \\
\hline Theme 11 & $\begin{array}{l}\text { The need to create and support cultures in which it is safe to take the type of risks } \\
\text { and tolerance and appreciation for what can be learned from failure to improve both } \\
\text { business process and organizational strategy. }\end{array}$ \\
\hline
\end{tabular}


Thompson (2010) and Chabursky (2005) suggested that the problems in projects can often stem from the inefficient or improper managing of the soft integrative elements of staffing, communications, quality, and risk. These soft elements, with the exception of risks, are behavioral elements that require active and attentive leadership from project managers in order to achieve desired project outcomes (Chabursky, 2005; Hyvari, 2006; Thompson, 2010). Project management literature suggests that projects usually fail not on technical merit, but on matters related to personnel (Chabursky, 2005; Hyvari, 2006; Thompson, 2010). Studies of successful project managers identify success factors, as the ability to manage people, stress, and communications (Chabursky, 2005; Hyvari, 2006; Thompson, 2010). The project manager's ability to successfully lead a team and achieve goals is and will always be critical to the success of a project (Hyvari, 2006).

Over the years organizations have identified that leadership is a key factor in achieving organizational effectiveness and efficiency (Thompson, 2010). Project management, while recognizing that leadership can contribute to successful project management has stopped short of specifically identifying leadership as the way forward for ensuring successful project results (Chabursky, 2005; Hyvari, 2006; Thompson, 2010). Previous research has indicated that being technically competent in the principles of project management does not usually ensure is not successful outcomes (Thompson, 2010; Thite, 2000). Many projects continue to fail despite the use of established project methods and techniques as the leadership competency required for successful project outcomes have been found lacking (Chabursky, 2005; Hyvari, 2006; Thompson, 2010). Leadership coaching can become a tool that assists in developing better decision making leadership skills in information technology project managers.

Elkins (2015) indicates that managers with higher levels of cognition and skill around leadershp perform more efficiently when tasked with managing multiple complex projects. Kouzes and Posner (2017) postulate the significance of increasing higher-level leadership thinking and decision-making, which are critical capabilities for senior leaders. Business cycles in the current organizational environment are tinier and more convoluted; hence, mandating for improved leadership comptencies (Burrell, Nobles, \& Aridi, 2018). The volatile nature of cybersecurity and information technology developments challenges project managers, cybersecurity professionals, and information technologists due to constant threats around the effective implimentation of emergening techologies, cybesecurity talent shortages, regulatory compliance, organizational risk management and finanical resource constraints (Burrell, Nobles, \& Aridi, 2018). 
The need for leadership development through executive coaching for cybersecurity and information technology project mangars should be a top priority given the rate that new technologies are integrated within the organizaton (Burrell, Nobles, \& Aridi, 2018), especially since, business leadership skills are becoming just as important as project management skills due to the digital convergence and interconnection between business operations and technical operations (Florentine, 2017).

Research by Thompson (2010) specifies that an operative leader has to often successfully engage the human, personal, and people on the project team towards in order to have success. These are skills that need to nurtured and developed and leadership coaching provides a means to improve how information technology and cybersecurity professionals lead projects and project teams.

\section{References}

[1] Anderson, A. (2011). Engaging resistance: How ordinary people successfully champion Change. Palo Alto, CA: Stanford University Press.

[2] Artto, A. Karlos, \& Dietrich, Perttu H. in Morris and pinto. (2014). Strategic business management through multiple projects. Hoboken, $\mathrm{NJ}$ : Wiley.

[3] Boyd, A. (2018, March). It Takes More Than Tech Skills To Be a Strong Cyber Leader. NextGov. Retrieved from: https://www.nextgov.com/cybersecurity/2018/03/it-takes-moretech-skills-be-strong-cyber-leader/146520/

[4] Burrell, D.N., Nobles, C. Aridi, A.S., (2018). The critical need for formal leadership development programs for cybersecurity and information teachnoloyg professionals. Proceedings of the 2018 International Conference on Cyber Warfare and Security, 82-91. Academic Conferences International Limited.

[5] Candis, Best, K., Magnolia, Smithfield. (2010). Assessing Leadership Readiness Using Developmental Personality Style: A tool for leadership coaching. International Journal of Evidence Based Coaching and Mentoring Vol. 8, No. 1, February 2010.

[6] Chabursky, L. (2005). Dramatically increase project success with radical QA: A guide to managing expectations and results. Journal of Quality Assurance Institute, 19(3), 29-36.

[7] Chartered Institute of Personnel and Development. (2010). Learning and Development 2010. Survey report. London. CIPD. Retrieved from: http://www.cipd.co.uk/binaries/5215_learning_talent_development\%20survey_report.pd

[8] Cunningham, Liz, McNally, Kimberly. (2003). Improving Organizational and Individual Performance through Coaching. A case Study by Mosby, Inc. 1067991x/2003/doi:10.1067/nrsi.2003.90

[9] Creemers, B. (2010). Improving quality of education: Dynamic Approaches to school Improvement. New York: NY: Routledge

[10] Duke, D. L. (2011). The challenge of school district leadership. New York , NY: Routledge. 
[11] Elkins, R. (2015). Business: Golden Nugget Methods for High Effectiveness - Leadership, Management \& Communication. Seattle, WA: CreateSpace Independent Publishing Platform.

[12] Ely, Katherine, Boyce, Lisa A., Nelson, Jonathan K., Zaccaro, Stephen J., Hernez-Broome,

[13] Gina, Whyman, Whayman, (2010). Evaluating Leadership Coaching: A review and integrated framework. The Leadership Quarterly.

Retrieved from: Journal homepage: www.elsevier.com/locate/leaqua

[14] Feldman, Daniel C., Lankau, Melenie J. (2010). Executive Coaching: A review and Agenda for Future Research. Journal of Management. DOI: 10.1177/0149206305279599.

[15] Feldman, D.C. (2001). Career coaching: what HR professionals and managers need to know. Human Resources Planning, 24: 26-35.

[16] Florentine, S (2017, February 27). IT project success rates finally improving. CIO. Retrieved from https://www.cio.com/article/3174516/project-management/it-project-success-ratesfinally-improving.html

[17] Freeman, A. M., \& Perry, J.A. (2010). Executive coaching under pressure: A case stud, consulting psychology journal :practice and Research, 6, 189-202

[18] Fenwick, F. J. \& Gayle, C. A. (2008). Missing Links in Understanding the Relationship Between Leadership and Organizational Performance. International Business \& Economics Research Journal Volume 7.

[19] Gray, E., David, Ekinci, Yuksel, and Goregaokar, Harshita. (2011). Coaching SME managers: business development or personal therapy? Faculty of management and law, university of Surrey. Guildford, UK. Business School, Oxford, DOI: 10.108/09585

[20] Hannafey, T., Francis, Vitulano. A. Lawrence. (2012). Ethics and Executive Coaching: An Agency Theory Approach. J Bus Ethics (2013) 115:599-603 DOI 10.1007/s10551-012- 1442-z

[21] Hyvari, I. (2006). Success of projects in different organizational conditions. Project Management Journal, 37(4), 31-41.

[22] Kampa-Kokesh, S., Anderson, M., (2005). Executive Coaching: A comprehensive Review of the Literature. Copyright 2001 by the Educational Publishing Foundation and the Society of Consulting Psychology, 1061^) 087A) I/\$5.00 DOI 10.1037//1061-4087.53.4.205.Consulting Psychology Journal: Practice and Research, Vol. 53, No. 4, 205-228.

[23] Kouzes, J., \& Posner, B., (2017). The Leadership Challenge: How to Make Extraordinary Things Happen in Organizations. Boston MA: Harvard Business Review Publishing.

[24] Khan, V., Hafeez, M., Rizfi, S. M., Hasanain, A., Maria, A. (2012). The relationship of leadership styles, employees commitment, and organization. Performance. European journal of economics, finance and administrative. ISSN: 1450- 227549.

[25] Lebihan, R. (2011). Business schools tap coaching trend. Australian Financial Review.

[26] Lester, D. L. \& Parnell, J. A. (2006). The Desktop Manager. S.A.M. Advanced Management Journal, 71(4), 43-49, 3.

[27] Lunenburg, F.C., \& Ometein, A. O. (2010). Educational administration: Concepts and practices. Thousands Oaks, CA: Wadsworth/Cengage Learning

[28] McCarthy, Grace, Milner, Julia. (2012). Managerial coaching: challenges, opportunities and Training. ydney Business School, University of Wollongong, School of Psychology, Deakin University, Melbourne, Australia. Journal of Management Development Vol. 32 No. 7, 2013 pp. 768-779 r Emerald Group Publishing Limited 0262-1711 DOI 10.1108/JMD-11-2011-0113.

[29] Mayfield, Jacqueline; Mayfield, Milton. (2012). the leadership relation between leader Motivating language and employee self-efficacy. A partial least squares model analysis. Journal of business communication. Doi: 10.1177/0021943612456036. 
[30] Northouse, Peter G. (2013). Leadership Theory and Practice. Western Michigan University. Sixth Edition

[31] Newsom. Glenn, Dent, B., Eric. (2011). A Work Behavior Analysis of Executive Coaches. International Journal of Evidence Based Coaching and Mentoring Vol. 9, No. 2, August 2011 Page 1.

[32] Obiwuru, Timothy, C.; Okwu, Andy T. Akpa, Victoria, O. Nwankwere, Idowu A. (2011). Effects of leadership style on organizational performance: A survey of selected small scale enterprise in Ikosia-Ketu counsil development area of Lagos state, Nigeria. Vol.1No.7 [100111] October-201.

[33] Oltsik, J. (2017). The life and times of cybersecurity professionals. ESG and ISSA: Research Report. Available at: https://www.esg-global.com/hubfs/issa/ESG-ISSA-Research-Report-Lifeof-Cybersecurity-Professionals-Nov-2017.pdf?hsCtaTracking=a63e431c-d2ce-459d-8787cc122a193baf\%7Ce74f0327-0bbc-444a-b7a8-e2cd08d1999e

[34] Paul, G.W. \&Berry, D.M. (2013). The Importance of Executive Leadership in Creating a PostMerged Organizational Culture Conducive to Effective Performance Management. SA Journal of Human Resources Management/SA

[35] Peterson, D.B., \& Hicks, M.D. 1995. The leader as coach: Strategies for coaching and Developing others. Minneapolis, MN: Personnel Decisions.

[36] Peltier, B. (2001). The psychology of executive coaching: Theory and Application. Ann Arbor, MI, Sheridan Books.

[37] Pellegrinelli, S., (2011). What's in a name? : Project and program? International Journal of Project Management, 29-(2), 232-240.

[38] Senge, Peter M. (2006). The Fifth Discipline: The Art and Practice of the Learning

[39] Organization. Cataloging in-Publication Data for the hardcover edition is on file with the Library of Congress. ISBN 978-0-385-51725-6

[40] Strang, K.D. (2011). Leadership substitute and personality impact on time and quality in virtual new product development project. Project Management Journal, 42(1), 73-90. doi:10.1002/pmj.20208

[41] Spector, B. (2011). Implementing organizational change: theory into practice-international edition. Upper Saddle River, NJ: Prentice Hall.

[42] Saowalux, P. \& Peng, C. (2007). Impact of Leadership Style on Performance: A Study of Six Sigma Professionals in Thailand. International DSI/Asia and Pacific DSI, July, 2007

[43] Thomas, F.N., Waits, R.A. and Hartsfield, G.L. (2007), "The influence of Gregory Bateson: legacy or vestige?" Kybernetes, Vol. 36 Nos 7/8, pp. 871-83...

[44] Thompson, K. N. (2010). Servant-leadership: An effective model for project management (Order No. 3423176). Available from ProQuest Dissertations \& Theses Global. (758921751). Retrieved from https://search-proquestcom.contentproxy.phoenix.edu/docview/758921751?accountid=35812

[45] Thite, M., (2000). Leadership styles in information technology projects. International Journal of Project Management, 18(4), 235-241.

[46] Vugt, Mark Van, Hogan, R., Kaiser, R. (2008). Leadership, Followership, and Evolution. 2008 American Psychologist Association 0003-066X/08. Vol. 63, No. 3, 182-196. DOI: 10.1037/0003-066x.63.3.182

[47] Visser, M. (2007b), "System dynamics and group facilitation: contributions from communication Theory", System Dynamics Review, Vol. 23 No. 4, pp. 453-63. 
[48] Wasylyshyn, K.M. (2003), "Coaching and executive character: core problems and basic approaches", Consulting Psychology Journal: Practice and Research, Vol. 55 No. 2, pp. 94106.

[49] Walker-Fraser, Alison. (2011). An HR perspective on executive coaching for organizational Learning. International Journal of Evidence Based Coaching and Mentoring Vol. 9, No. 2, August 2011

[50] Wenson, E., Jennifer. (2010). After-coaching leadership skills and their impact on direct reports: Recommendations for organizations. After-coaching leadership skills and their impact on direct reports: recommendations for organizations. Human Resource Development International Vol. 13, No. 5, November 2010, 607-616.

[51] Wysocki, R.K. (2014). Effective Project Management: Traditional, agile, extreme ( $7^{\text {th }}$ ed.). 